\title{
The Therapeutic Use of Propolis Extract in Alveolar Bone Contaminated with Bacterial Endotoxin
}

Yamba Carla Lara Pereira ${ }^{1}$, João Paulo Mardegan Issa ${ }^{2}$, Evandro Watanabe ${ }^{2}$, Glauce Crivelaro Nascimento ${ }^{2^{*}}$, Mamie Mizusaki lyomasa ${ }^{2}$, José Orestes Del Ciampo $^{3}$ and Edilson Ervolino 4

${ }^{1}$ FOP UNICAMP-Faculdade de Odontologia de Piracicaba Universidade Estadual Paulista UNICAMP, Brazil

${ }^{2}$ FORP USP Faculdade de Odontologia de Ribeirão Preto Universidade de São Paulo, Brazil

${ }^{3}$ Faculdade de Ciências Farmacêuticas de Ribeirão Preto FCFRP USP, Brazil

${ }^{4}$ Faculdade de Odontologia de Araçatuba UNESP, Brazil

"Corresponding author: Glauce Crivelaro Nascimento, PhD, FORP USP Faculdade de Odontologia de Ribeirão Preto Universidade de São Paulo, Brazil, Tel: +551633154050; E-mail: glau_nascimento@yahoo.com.br

Received date: February 23, 2018; Accepted date: March 05, 2018; Published date: March 12, 2018

Copyright: (C) 2018 Pereira YCL, et al. This is an open-access article distributed under the terms of the Creative Commons Attribution License, which permits unrestricted use, distribution, and reproduction in any medium, provided the original author and source are credited.

\begin{abstract}
Propolis is a resinous substance obtained by bees, whose antibacterial, anti-inflammatory, antiviral, antifungal, immune stimulant, and local anesthetic wound healing properties have been considered for clinical practice. In particular, its anti-inflammatory and antibacterial characteristic seems to be a novel target for infectious process from dental origin. This work aimed to evaluate the propolis antibacterial potential against a bacterial endotoxin on dental alveoli. First, some properties of green propolis extract were analyzed (in vitro): 1) physicochemical profile 2) Minimum Inhibitory Concentration (MIC) against endotoxin from Gram negative Escherichia coli, and 3) its immunoregulatory activity on leukocytes from the spleen of rats. Then, an inflammatory process was induced in rats by a contamination with lipopolysaccharide (LPS) that is recognized as an endotoxin. For this purpose, rats were subjected to extractions of maxillary first molars, right and left, which immediately had the right dental socket contaminated with $0.1 \mathrm{~L}$ of LPS $(100 \mu \mathrm{g} / \mathrm{kg})$. After 14 days from exodontia, these individuals were divided in groups treated with Pure Propolis Extract (EPP) and groups without therapy. The contaminated alveolar bone or the same area from animals without inflammation-induced were removed for histological and immunohistochemical processing. Our data reveal an important therapeutic action from green propolis. In vitro tests indicated low cytotoxicity for this compound. By a hematoxilin and eosin analysis, the group infected and treated with propolis presented the alveoli with more new bone tissue, characterized by bony trabeculae circling small cavities filled by a loose connective tissue containing blood vessels. Additionally, a histochemical marker of osteoclasts, tartrateresistant acid phosphatase (TRAP), was used to determine the new bone formation rate. The propolis induced more TRAP formation on alveolar bone infected by LPS. Our findings highlight the potential of propolis to be applied in dental material.
\end{abstract}

Keywords: Endotoxin; Lipopolysaccharide (LPS); Propolis; Bone repair; Rats

\section{Introduction}

Propolis is a resinous substance obtained by bees which the harvest comes from substances secreted by plants and appears to be responsible for sealing and sterilization [1,2]. Propolis composition depends on the geographic region where it was extracted, the species of bees involved, as well as the extraction method employed [3]. They appear commercially as Ethanol Extract of Propolis (EEP) in varied concentrations or as Pure Propolis Extract (EPP) [4]. Literature has demonstrated the antibacterial, anti-inflammatory, antiviral, antifungal and immune stimulant properties for propolis. Also, it has been widely recognized its anticancer and antioxidant effects. Further, its wound healing acceleration function is highlighted [5-9].

Considering its protective properties, propolis has attracted attention as an antimicrobial agent. Global trends for natural products have stimulated for further research for the medical ability of propolis. Propolis has been used for thousands of years as a popular medicine. In dentistry, it has been used to control the oral microflora [10].
Bacteria are microorganisms that induce inflammatory reaction, the major causes of diseases [11]. Gram-negative bacteria that has endotoxin in its composition, has major pathogenicity property $[12,13]$, leading to severe inflammatory processes [14]. An important endotoxin used for experimental studies is the lipopolysaccharide (LPS), which is associated with production of some mediators such as cytokines, prostaglandins and nitric oxide itself [15]. In oral cavity, LPS cling irreversibly absorbed to tissues such as bone and cementum, perpetuating local inflammatory response [16-18]. About that, various treatments have been proposed aiming at a guided regeneration of bone tissue, using various combinations of bone grafts $[19,20]$. It is stated that the endotoxins of living or dead bacteria, intact or in fragments, act on macrophages, neutrophils and fibroblasts, triggering the release of various chemical mediators and inflammatory cytokines or bioactive [21].

Using an animal model of LPS-induced contamination on dental alveoli, we aimed to analyze the therapeutic effects of propolis on alveolar bone. We hypothesized that propolis may represents an economic alternative for treatment of surgical areas in hard tissues especially in areas contaminated with bacterial endotoxin. For this proposition, it was studied in vitro properties of the extract green propolis (Minimum Inhibitory Concentration (MIC); 
immunoregulatory activity of leukocytes from spleen (cytotoxicity) and physicochemical profile). Then, it was analyzed the propolis effect in vivo studies, by a histological and immunohistochemical investigation of alveolar bone of rats [22].

\section{Materials and Methods}

\section{Collection folder-based extract of propolis}

Propolis chosen to serve as a substrate for this work was the Green Propolis, collected in January 2005, at Capetinga city (Minas Gerais, Brazil). The choice of Green Propolis was determined, both for its easy handling and predominant inflammatory characteristic [4]. Attainment of the primary active ingredients of propolis was performed using $30 \mathrm{~g}$ of powdered propolis in $100 \mathrm{~mL}$ of $70 \%$ ethanol at room temperature, and macerated for 48 hours and stirred six times a day [4]. The separation of propolis extract by decanting of the waste was preceded by a vacuum filtration, then taken to the rotary evaporator at 115 revolutions per minute $(\mathrm{rpm}) 80^{\circ} \mathrm{C}$. Once transferred to an amber glass remained in the oven at $45^{\circ} \mathrm{C}$ for 07 days, seeking out the water glass that eventually was capped tightly and stored at room temperature.

\section{Determination of chemical profile of the sample of green propolis}

Propolis samples were ground and ethanol extracts were prepared, as follows: $30 \mathrm{~g}$ propolis/100 $\mathrm{mL}$ ethanol (70\%). The solutions were left at room temperature for 20 days and shaken once a day. After filtration, the solvents were totally evaporated in a water bath, at temperatures not exceeding $50^{\circ} \mathrm{C}$.

\section{Thin layer chromatography and bioautography}

Thin-layer chromatography (TLC) plates (silica gel60-GF254; Merck, Darmstadt, Germany) received $5 \mathrm{ul}$ of the propolis solutions. All solvents were purchased from Merck. Three mobile phases were tested, two according to Nieva Moreno et al. (2000) and pure chloroform. The plates were visualized using sulphuric vanillin (Costa 1986). Bioautography was carried out after airing the TLC platesfor over $8 \mathrm{~h}$ (Metzner et al. 1975). The plates were covered with $20 \mathrm{ml}$ sterile Sabouraud agar at $45^{\circ} \mathrm{C}$, inoculated with the saline suspension of Candida, incubated for $24 \mathrm{~h}$ at $37{ }^{\circ} \mathrm{C}$, then covered with a $1 \%$ aqueous solution of 2,3,5-triphenyl tetrazoline chloride and incubated for another $24 \mathrm{~h}$ at $37^{\circ} \mathrm{C}$. Inhibition zones were visualized as clear areas against a red background. Preparative TLC plates were used to isolate the components of propolis. These were scraped from the plates, eluted with methanoland identified by high performance liquid chromatography (HPLC) [23]. Simultaneously, phenolic standards were chromatographed under the same conditions.

\section{Minimum Inhibitory Concentration (MIC)}

Obtaining the primary active ingredients of the propolis was carried out using $30 \mathrm{gm}$ of propolis sprayed in $100 \mathrm{ml}$ of $70 \%$ alcohol at room temperature. Propolis MIC was determined using macro E test strips (AB Biodisk) on Mueller-Hinton agar with American Type Culture Collection (ATCC) 25922 as control. A sterile swab was sunk into the Escherichia coli suspension and then inocula onto Muller-Hinton 5\% defibrinated sheep blood agar plates and after 15 to $20 \mathrm{~min}$, when the bacterial suspension were absorbed onto the medium, propolis MIC strips were applied on the plate.

MIC tests used a 96-well round-bottom microtiter plate with propolis concentrations ranged from 400, 350, 300, 250, 200, 190, 180, $170,160,150,140,130,120,110,100,90,80,70,60$ and $50 \mu \mathrm{g} / \mathrm{mL}$. The microplaque was incubated for $24 \mathrm{~h}$ at $37^{\circ} \mathrm{C}$. After an overnight incubation, $5 \mu \mathrm{l}$ resazurin $\left(6.75 \mathrm{mg} \mathrm{ml}^{-1}\right)$ was added to all wells and incubated at $37^{\circ} \mathrm{C}$ for another $4 \mathrm{~h}$. Changes of color was observed and recorded. On completion of the incubation, columns with no colour change (blue resazurin colour remained unchanged) were scored as above the MIC value.

\section{In vitro cytotoxicity assay}

For cytotoxicity analysis, spleens were surgically removed from the rats, and then ground using a stainless steel sieve $(0.01 \mathrm{~mm}$ porosity) in Petri dish containing $4 \mathrm{~mL}$ of RPMI-1640 medium (GIBCO Invitrogen) supplemented with $10 \% \mathrm{HS}, 5 \% \mathrm{FBS}, 100 \mathrm{U} / \mathrm{ml}$ penicillin and $100 \mathrm{mg} / \mathrm{l}$ streptomycin. The culture medium containing splenic cells (free of cell / tissue debris) was collected and centrifuged at 1000 rpm for 15 minutes at $10^{\circ} \mathrm{C}$ and suspended in RPMI medium for counting.

The in vitro cytotoxicity of propolis formulations in the presence of Wistar rat spleen cells was assessed by 3-(4.5-dimethylthizol-2- yl)-2.5diphenyl tetrazolium bromide (MTT) (Sigma, MO, USA). Briefly, cells maintained in continuously logphase growth were detached with $0.05 \%$ trypsin and $0.02 \%$ EDTA in calcium-free phosphate-buffered saline (PBS), and washed 3 times with DMEM at $1000 \mathrm{rpm}$ for $15 \mathrm{~min}$ at $10^{\circ} \mathrm{C}$. Cells were placed in 24 -well plates with $2 \mathrm{~mL}$ of media per well at a density of $3 \times 105$ cells per well. After $24 \mathrm{~h}$ of culture, the media was removed and fresh media with different concentrations of propolis formulations was added to the wells. At the end, the cells were incubated for $24 \mathrm{~h}$ in the following manners: retreating with the propolis formulations and control, by replacing the cell exposed media with fresh media. As such, the medium was replaced and $100 \mu \mathrm{L}$ of MTT $(5 \mathrm{mg} / \mathrm{mL}$ ) was added, and then the cells were incubated for a further $3 \mathrm{~h}$ at $3^{\circ} \mathrm{C}$. Subsequently, the formed formazan crystals were dissolved in $500 \mu \mathrm{L}$ of $20 \%$ sodium dodecylsulfate solution acidified with $\mathrm{HCl} 0.01 \mathrm{~mol} / \mathrm{L}$ overnight. The absorbance of each well was measured at $570 \mathrm{~nm}$ using a $\mu$ Quant ELISA microplate reader (BioTek Instruments, Winooski, VT). The cytotoxic activity was measured in a spectrophotometer using a $570 \mathrm{~nm}$ interference filter.

The cytotoxic rate was calculated as follows: \%Cytotoxicity = $ð 1$-absorbance cells treated absorbance untreated cells $\times 100$. The cytotoxicity of the propolis formulations in the absence of the current was also verified.

\section{Animals}

We selected 32 male animals of the type Rattus norvegicus albinus rats, Rodentia, Mammalia Wistar with body weight ranging between 200 and 250 grams, aged approximately 40 days, receiving food and water ad libitum. They were housed in boxes of four animals each, with free access to food and water, under controlled temperature $\left(23 \pm 1^{\circ} \mathrm{C}\right)$ and light/dark cycle of 12/12 hours.

This project was submitted to the Board of Ethics in the Use of Experimental Animals Campus USP, Ribeirão Preto, and obtaining approval under paragraph 091.1.1538.53.5 (Table 1). 
Citation: Pereira YCL, Issa JPM, Watanabe E, Nascimento GC, lyomasa MM, et al. (2018) The Therapeutic Use of Propolis Extract in Alveolar Bone Contaminated with Bacterial Endotoxin. Dentistry 8: 473. doi:10.4172/2161-1122.1000473

Page 3 of 9

\begin{tabular}{|l|l|}
\hline Groups & Treatments \\
\hline CN R (Negative Control-right) & Rats with LPS-induced contamination and without treatment \\
\hline CN L (Negative Control-left) & Rats without contamination and without treatment \\
\hline EPP R (Pure Propolis Extract-right) & Rats without contamination and treated with local application of Pure Propolis Extract (EPP) \\
\hline EPP L (Pure Propolis Extract-left) & Rats with LPS-induced contamination and treated with local application of Pure Propolis Extract (EPP) \\
\hline
\end{tabular}

Table 1: Experimental groups.

Tooth extraction and contamination of wells with lipopolysaccharide (LPS) and treatment: The animals were anesthetized with Xylazine $10 \mathrm{mg} / \mathrm{kg}$ and Ketamine $80 \mathrm{mg} / \mathrm{kg}$ body weight and subjected to extractions of maxillary first molars left and right with the aid of "Hollemback and anatomical clamp after prior tissue separation. Immediately after tooth extraction, the animals had the right wells contaminated with $0.1 \mu \mathrm{L}$ of bacterial lipopolysaccharide (LPS) at a concentration of $100 \mathrm{mg} / \mathrm{kg}$ ( $\mathrm{Li}$, et al Khansari., 2002), derived from the cell wall of Escherichia coli (Sigma, St. Louis, MO, USA) suspended in saline, while left the wells were not contaminated. This contamination was possible through a millimeter Hamilton ${ }^{\bullet}$ syringe coupled to a polyethylene tube (P10), to avoid contamination of the instrument [24-26].

The wells on the right side of the control and treated groups with propolis were exposed to endotoxin, while wells on the left side were not contaminated and served as control.

Animal sacrifice and perfusion: At the end of the 14-day survival period after the exodontia, deep anesthesia was performed by an overdose of association of $10 \%$ ketamine hydrochloride $(225 \mathrm{mg} / \mathrm{kg}$ ) and $4 \%$ xylazine $(30 \mathrm{mg} / \mathrm{kg})$. Then the rats were euthanized by means of breaking the diaphragm, which was carried out via transcardiac perfusion with phosphate buffered saline (PBS; $0.01 \mathrm{M}, \mathrm{pH}=7.4$ ), followed by a $4 \%$ paraformaldehyde solution. The maxilla was removed, dissected, and kept in a 10\% ethylenediaminetetraacetic acid (EDTA) until its complete decalcification. The samples were left in sodium sulfate during $24 \mathrm{~h}$ to be dehydrated and embedded in paraffin. Two parallel cuts were performed parallel to each other, perpendicular to the occlusal plane of the upper molars, and tangential to the mesial surface of the maxillary first molar to obtain a fragment containing the roots of the molars.

Histological processing and quantification: From each sample, cuts were carried systematized $6 \mu \mathrm{m}$ thick, which were stained with hematoxylin-eosin (HE) and the images were captured at magnification 10x using a Leica MZ125 light microscope (Leica Microsystems, Germany) connected to a digital camera.

The images obtained from HE coloration were quantified as the following procedure: analysis of the amount of bone formation in the alveoli of each animal was performed using the Method of Differential Count Point, where a test system of 108 points was superimposed on images of 07 fields previously captured in $20 \mathrm{x}$ increase. The pictures were analyzed to determine the relative percentage of newly formed bone $(\mathrm{Vv})$ in relation to the bone. This relationship was determined between the points that were on newly formed bone $(\mathrm{Pp})$ and total points of the grid test $(\mathrm{Pt})$, represented by the following formula: $\mathrm{Vv}=$ Pp / Pt (\%) [24].
TRAP immunohistochemistry: Tartrate-resistant acid phosphatase (TRAP), once considered to be just a histochemical marker of osteoclasts is now recognized to be a molecule of widespread occurrence with functions in both the skeleton and the immune system. TRAP is expressed by osteoclasts, macrophages, dendritic cells and a number of other cell types [25]. The immunoreactivity showed TRAP in the alveolar bone was distributed throughout the cervical apex, with a clear preponderance less frequently noted in the deeper laminae. The samples were fixed with $4 \%$ paraformaldehyde and stained for tartrate-resistant acid phosphatase (TRAP) - activity as described previously [26]. TRAP positive cells were counted under the same magnification by a blinder evaluator under an optical microscope in three categories, mononuclear, multinuclear (2-10 nuclei) and giant (greater than 10 nuclei).

Using ten images, it was quantified all osteoclasts marked by immunohistochemical reaction in all experimental proposed groups.

Statistical analysis: According to the normal data distribution, we proceeded to test the factorial ANOVA with two fixed factors of variation (treatments and use of endotoxin) and Tukey-Kramer test $(\mathrm{p}<0.05)$.

\section{Results}

\section{In vitro}

Determination of chemical profile of the sample of green propolis: Quality control and standardization of green propolis sample were performed by a validated method (Souza, De Souza et al. 2007; De Sousa Da Silva Filho et al., 2009) by chromatographic technique (Figure 1). 


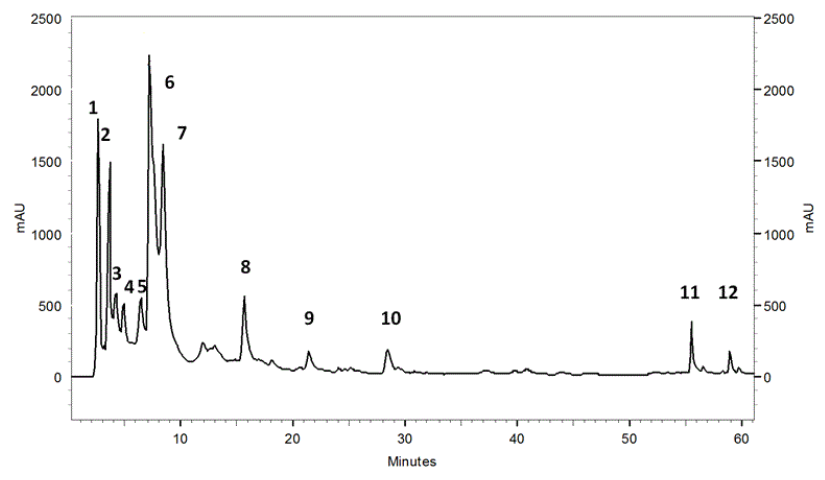

Figure 1: Characterization of green propolis compounds; Profile of Chromatography HPLC method for the green propolis sample characterizing the following substances: 1-caffeic acid, 2-coumaric acid, ferulic acid, 3, 4-cyanic acid, 5-AME, 6-Drupanin, 7Isosacuretin, 8-Artepellin, 9-Baccharin, 10-DCBE, 11- and 12 IS-SS.

From the knowledge of the chromatographic profile of this sample of propolis could be characterized as predominant components: caffeic acid (1), coumaric acid (2), Drupanin (6) and Isosacuretin (7).

Determination of minimum inhibitory concentration (MIC): The MIC can be defined as the lowest concentration of an antibiotic agent capable of inhibiting the action of a microorganism. At concentrations of $400 \mathrm{ug} / \mathrm{ml}$, green propolis inactivated Escherichia coli action (ATCC 25922) in this work.

Cytotoxicity: The propolis samples studied showed no cytotoxicity in spleni cells of Wistar rats.

\section{In vivo}

Propolis treatment induces increase in neoformed tissue on contaminated dental alveoli: Qualitative analysis of Hematoxilin and Eosin: The analysis of the alveolar bone treated with Pure Propolis Extract (EPP) on contaminated dental alveoli or not with LPS and stained with hematoxylin and eosin. Histological analysis of the alveoli after 14 days of tooth extraction presented similar characteristics between groups (A) contaminated or not contaminated (B) with LPS. The bone trabeculae revealed osteocytes in lacunae and osteoblasts flattened on the outskirts. It was observed between bone trabeculae a fibrous connective tissue with blood vessels by filling large cavities. The group infected and treated with propolis (C) presented the alveoli with more new bone tissue, characterized by bony trabeculae circling small cavities filled by a loose connective tissue containing blood vessels. The plot of uncontaminated and group treated with propolis (D) revealed bone trabeculae with osteocytes and osteoblasts assets on the periphery on the osteoid tissue. In these trabeculae, it was observed a fibrous connective tissue with numerous capillary filling large cavities (Figure 2). 
Citation: Pereira YCL, Issa JPM, Watanabe E, Nascimento GC, lyomasa MM, et al. (2018) The Therapeutic Use of Propolis Extract in Alveolar Bone Contaminated with Bacterial Endotoxin. Dentistry 8: 473. doi:10.4172/2161-1122.1000473

Page 5 of 9
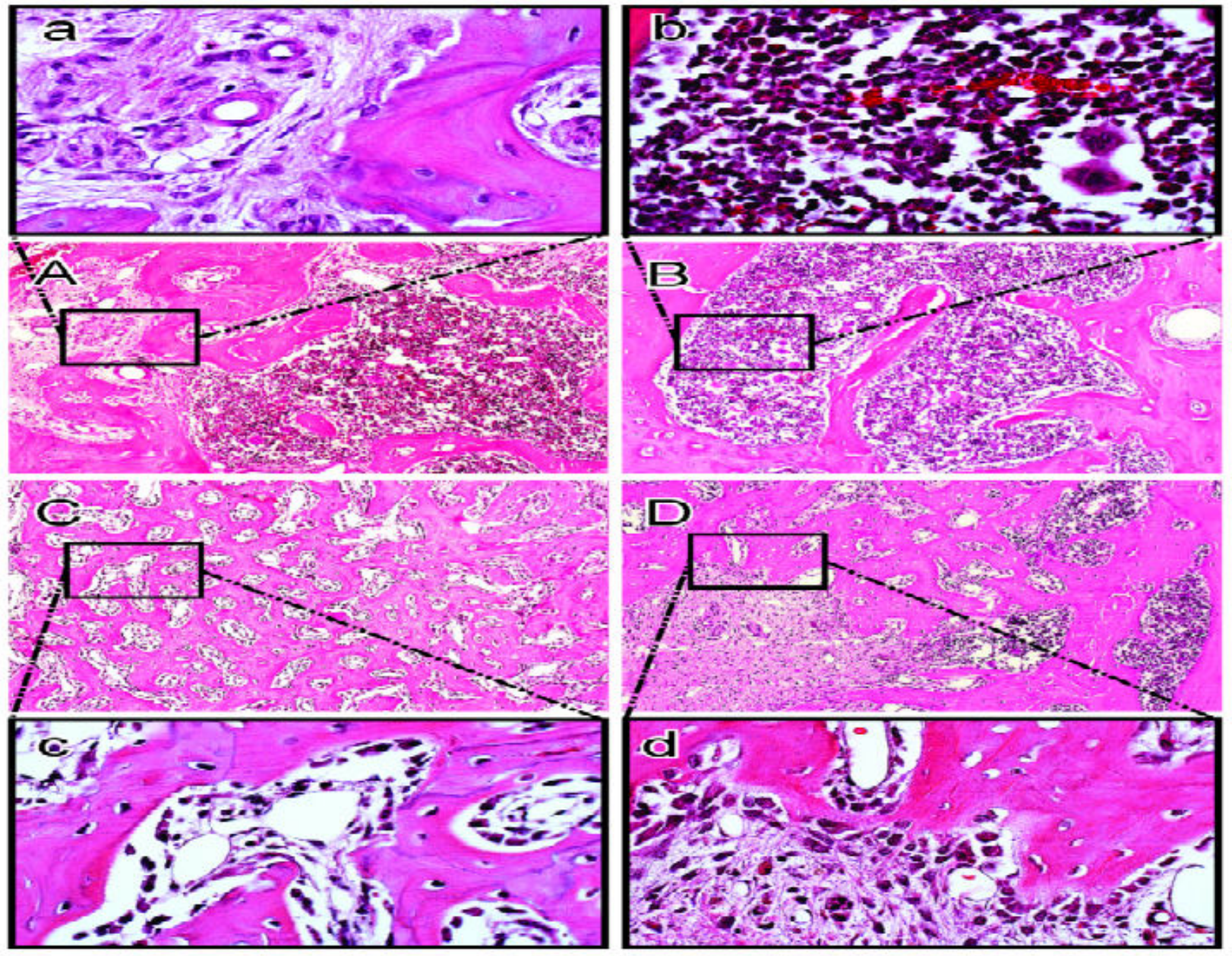

Figure 2: Propolis treatment induces increase in neoformed tissue on contaminated dental alveoli. Qualitative analysis: Photomicrographs from alveolar bone of rats stained with hematoxylin and eosin. A (10x) and a (40x): alveolar bone from rats without contamination and without treatment. B (10x) and b (40x): alveolar bone from rats with LPS-induced contamination and without treatment. C (10x) and c (40x): alveolar bone from rats without contamination and treated with local application of propolis. D (10x) and $\mathrm{d}(40 \mathrm{x})$ : alveolar bone from rats with LPS-induced contamination and treated with local application of propolis.

Propolis treatment increase bone formation on contaminated dental alveoli: Quantitative analysis of Hematoxilin and Eosin: The green propolis induced higher bone formation in dental alveoli infected with bacterial lipopolysaccharide, as compared to other groups. There was no statistical difference $(\mathrm{p}<0.05)$ between groups $\mathrm{CN} \mathrm{R}$ (negative control right - with endotoxin) and CN L (negative control without left-endotoxin) (Figure 3). 


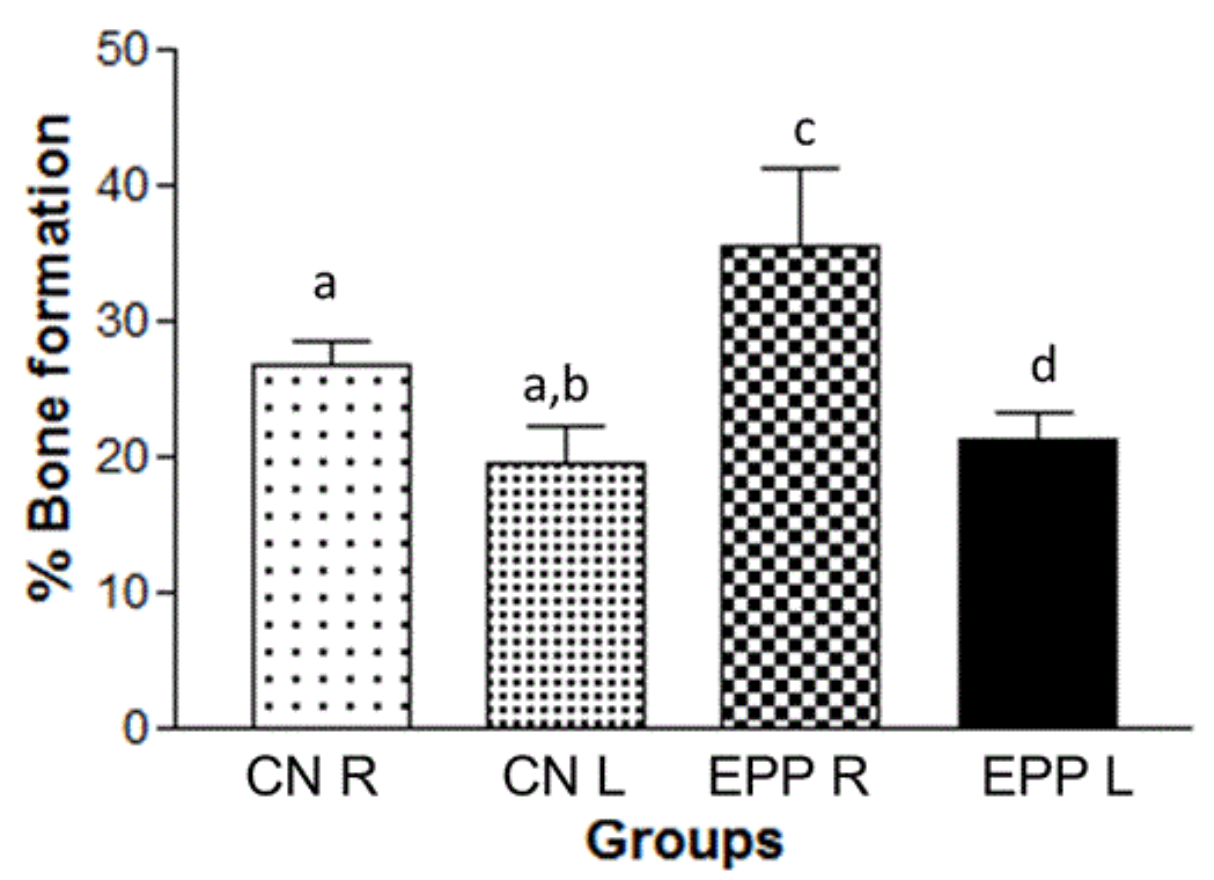

$\ldots$ CN R 觜 CN L $\infty$ EPP R EPP L

Figure 3: Propolis treatment increase bone formation on contaminated dental alveoli; Quantitative analysis: Results of the quantification of histology for hematoxilin and eosin for new bone formation in infected dental alveoli (right - R) or not (left - L) with bacterial lipopolysaccharide. Group CNR means rats with LPS-induced contamination and without treatment. Group CNL reflect rats without contamination and without treatment. Group EPP R means rats without contamination and treated with local application of Pure Propolis Extract (EPP). Group EPP L indicate rats with LPS-induced contamination and treated with local application of Pure Propolis Extract (EPP). Data presented as mean \pm SEM. a $p<0.05$ compared to EPP $R$ group. $b \mathrm{p}<0.05$ compared to $\mathrm{CN} R$ group. $\mathrm{c} p<0.05$ compared to all other experimental groups. $\mathrm{d} p<0.05$ compared to EPP R group.

Propolis treatment increases TRAP on contaminated dental alveoli: This ratio allowed to evaluate the new bone formation on the number of the osteoclasts found. The values were taken to the Prism 3.0, and the results showed that there was a statistical difference $(\mathrm{p}<0.05)$ between the group treated with green propolis and contaminated with LPS compared to the group treated with propolis, but without contamination (Figures 4 and 5). 

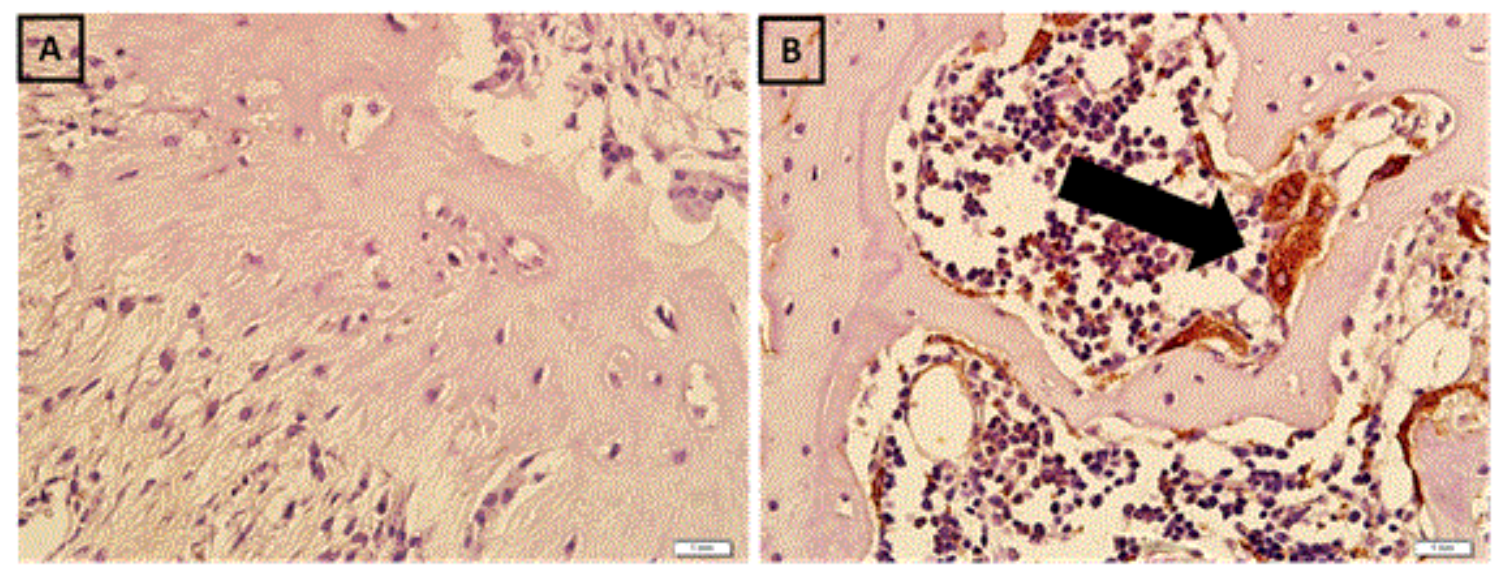

Figure 4: Propolis treatment induces increase in osteoclasts cells on contaminated dental alveoli. Qualitative analysis: Photomicrographs of the immunohistochemical reaction for TRAP (40x). A (10x): alveolar bone from rats with LPS-induced contamination and without treatment. B (10x): alveolar bone from rats with LPS-induced contamination and treated with local application of propolis.

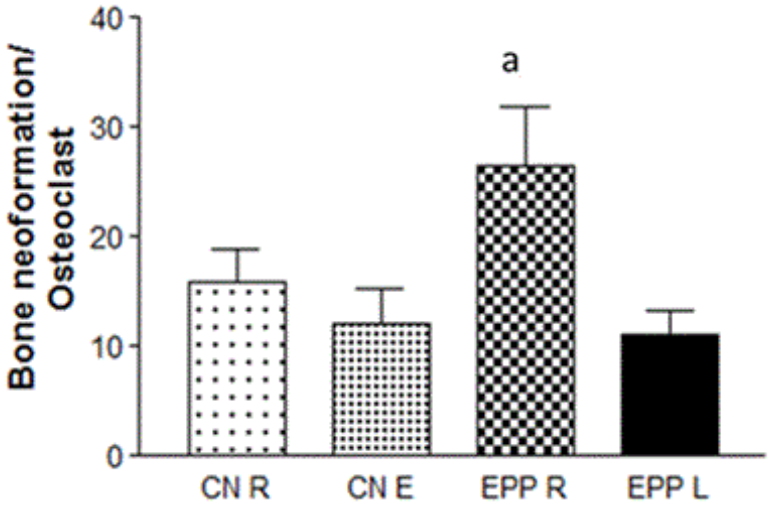

Figure 5: Propolis treatment increases TRAP on contaminated dental alveoli. Quantitative analysis: Results of the quantification of TRAP immunohistoquimistry in infected dental alveoli (right - R) or not (left - L) with bacterial lipopolysaccharide. Group CNR means rats with LPS-induced contamination and without treatment. Group CNL reflect rats rats without contamination and without treatment. Group EPP R means rats without contamination and treated with local application of Pure Propolis Extract (EPP). Group EPP L indicate rats with LPS-induced contamination and treated with local application of Pure Propolis Extract (EPP). Data presented as mean \pm SEM. a $\mathrm{p}<0.05$ compared to all other experimental groups.

\section{Discussion}

Propolis has enormous medical and economic importance, being marketed in several pharmaceutical and cosmetic preparations such as toothpastes, lotions, facial creams, tinctures, ointments, and others $[27,28]$. It has been observed a significant increase in the public interest for this product, in the number of bee breeders who invests in improving the production of propolis and in processing companies of this material [29]. Propolis was introduced into dentistry in 1969 by Mostrova, who's showed anesthesia action of this substance [30].

About the therapeutic potential of propolis in oral pathologies, Durate et al. reported that fatty acids in propolis provide a cariostatic effect by decreasing the tolerance of microorganisms to low $\mathrm{pH}$ and slowing down acid production [31]. Also, multiple and diverse effects of propolis on oral health have led to its use in periodontal diseases and propolis-based toothpastes should be used as adjuncts to other substances in individuals who are at a higher risk for periodontalrelated problem [32]. Again, literature have shown that propolis along with other cavity disinfectants, i.e. APF (acidulated phosphate fluoride) gels, diode lasers and $2 \%$ chlorhexidine, was used against S. mutans and L. bacilli and it was observed that there was a significant decrease in bacterial counts [33]. An in vitro and in vivo study revealed that propolis has a strong anti-inflammatory effect and can be used as a pulp capping agent [34]. Interesting, the knowledge about propolis effect on alveolar bone repair is poorly investigated. In this context, our data highlight the positive actions from propolis on infected alveolar bone in an animal model.

HPLC in the gradient mode and coupled with photodiode array detection remains the method of choice for the assay of most relevant components of propolis [35]. Using HPLC method, our data revealed that the prevalent components in propolis used here were: caffeic acid (1), acid coumaric (2), Drupanin (6), and Isosacuretin (7). The propolis employed in this study is reported in the literature changing the taxis of fibroblasts, and caffeic acid (CAPE), responsible for altering the proliferation of fibroblasts in lung [36]. In fact, the antioxidant property of propolis seems to be attributed to its radical scavenging ability, which was better than vitamin $\mathrm{C}$ and the antiinflammatory property is associated to the presence of caffeic acid phenethyl ester [37].

The sample used in this work showed also no cytotoxicity in leukocyte sowner ship of the spleen. This is an essential characteristic. In fact, the application of propolis mouthwashes on gingival fibroblasts shows less cytotoxicity than chlorohexidine mouthwashes [38]. In addition, Gebara et al reported that in vitro use of propolis extracts not only had antimicrobial activity against periodontopathic bacteria 
(Capnocytophagagingivalis, Prevotella intermedia, Fusobacterium neucleatum, Porphyromonas gingivalis) but also against microorganisms that cause supra-infection (Staphylococcus aureus, Escherichia coli, and Candida albicans). In particular, our work showed that at concentrations of $400 \mathrm{ug} / \mathrm{ml}$, green propolis inactive actions of Escherichia coli [39].

This work studies a contamination of alveolar bone induced by LPS in rats. Some studies have shown that the bone surfaces exposed to LPS induce signal transduction activating receptor 4 (TLR4), perpetuating the inflammatory response and the consequences for this tissue $[40,41]$. Ossola et al 2012, induced periodontitis by injecting LPS $(1 \mathrm{mg} / \mathrm{ml})$ into the gingiva around the first upper and lower molars, and into the inter-dental space between the first and second molars [42]. The mechanism by which LPS alter bone tissue is not completely clarify, but some authors suggest that the induction of the cascade of arachidonic acid metabolism via cyclooxygenase (COX) and lipoxygenase (LOX) is the mechanism of action of lipopolysaccharide on bone surfaces [42].

Bone remodeling is a process of continuous resorption and formation/mineralization carried out by osteoclasts and osteoblasts, which along with osteocytes, comprise the bone multicellular unit. Observations that osteoclast activity was dependent on the presence of functioning osteoblasts have spawned numerous hypotheses to explain the observed functional coupling [43]. Mineralization and resorption are inversely regulated by a number of factors, including cytokines, hormones, and substances such as osteoprotegerin (OPG) and receptor activator of NF-kB ligand (RANKL) [44].

Osteoclasts, cells stained by TRAP immunohistochemical technique in the present investigation, are bone-resorbing multinucleated cells derived from hematopoietic progenitors of the monocyte-macrophage lineage [45]. The differentiation of osteoclasts is tightly regulated by bone-forming osteoblasts. Many inflammatory cytokines, such as IL-1 and members of the TNF family, promote osteoclastogenesis in concert with RANKL [46]. Pileggi et al. 2009 showed for the first time the effect of propolis on both osteoclast formation and maturation [47]. Additionally, histological and morphological studies established that application of propolis systematically prevents bone loss in periodontal dysfunctions in rats [48]. In accordance, our results reveal an increase TRAP staining on infected alveolar bone treated with propolis for 14 days. In the same line, we evidence an acceleration of bone formation induced by propolis by histologic characteristics of alveolar bone from rats treated with local propolis. The experimental period proposed in this research (2 weeks) was based on published studies that demonstrated the high bone formation in calvaria bone defects after injury, and that these maximum indices of osteogenesis were seen from the 4 weeks.

From the collected data in this experimental model we can conclude that the pure green propolis treatment for an oral infection induced by bacterial lipopolysaccharide favored bone formation. Together, these results increase the understanding of propolis properties in an altered condition in oral environmental, stimulating the use of this compound for local intraoral therapies and the new studies to recognize complete mechanisms of action of this natural substance.

\section{Conflict of Interests}

All authors of this manuscript do not present conflict of interest.

\section{References}

1. Krol W, Czuba Z, Scheller S, Gabrys J, Grabiec S, et al. (1990) Antioxidant property of ethanolic extract of propolis (EEP) as evaluated by inhibiting the chemiluminescence oxidation of luminol. Biochem Int 21: 593-597.

2. Moţ A, Soponar F, Sârbu C (2010) Multivariate analysis of reflectance spectra from propolis: geographical variation in Romanian samples. Talanta 81: 1010-1015.

3. Banskota A, Tezuka Y, Kadota S (2001) Recent progress in pharmacological research of propolis. Phytother Res 15: 561-571.

4. Farnesi AP (2007) Efeitos da própolis de abelhas africanizadas e meliponíneos em microorganismos. Dissertação de Mestrado.

5. Pontin K, Da Silva Filho A, Santos F, Silva M, Cunha W, et al. (2008) In vitro and in vivo antileishmanial activities of a Brazilian green propolis extract. Parasitol Res 103: 487-492.

6. Da Silva Filho A, De Sousa J, Soares S, Furtado N, Andrade e Silva M, Cunha W, et al. (2008) Antimicrobial activity of the extract and isolated compounds from Baccharis dracunculifolia D. C. (Asteraceae). Z Naturforsch C 63: 40-46.

7. Sakai K, Yamanami T (2006) Thermotolerant Bacillus licheniformis TY7 produces optically active 1-lactic acid from kitchen refuse under open condition. J Biosci Bioeng 102: 132-134.

8. Valera M, Da Rosa J, Maekawa L, De Oliveira L, Carvalho C, et al. (2010) Action of propolis and medications against Escherichia coli and endotoxin in root canals. Oral Surg Oral Med Oral Pathol Oral Radiol Endod 110: 70-74.

9. De Rezende G, Da Costa L, Pimenta F, Baroni D (2008) In vitro antimicrobial activity of endodontic pastes with propolis extracts and calcium hydroxide: a preliminary study. Braz Dent J 19: 301-305.

10. Baranwal R, Duggi V, Avinash A, Dubey A, Pagaria S, et al. (2017) A Smart Supplement for an Intracanal Medicament. Int J Clin Pediatr Dent 10: 324-329.

11. Ferreira BJ, Souza MeF, Soares Filho AM, Carvalho AA (2009) The historical evolution of dengue prevention and control programs in Brazil. Cien Saude Colet 14: 961-972.

12. Seixas F, Garrido A, Vieira M, Pécora J, Saquy P, et al. (2002) Clinical aspects of pulpal-periodontal lesions. Aust Endod J 28: 82-85.

13. Rocha R, Silva R, Assed S, Medeiros A, Faccioli L, et al. (2009) Nitric oxide detection in cell culture exposed to LPS after Er:YAG laser irradiation. Int Endod J 42: 992-996.

14. Hojlo MM, Hugowski C, Szymaniec S, Splawska KA (2007) Experimental uveits induced by different uniform salts of enterobacterial lipopolysaccharides. Postepy Hig Med Dosw 61: 606-611.

15. Li L, Khansari A, Shapira L, Graves D, Amar S (2002) Contribution of interleukin-11 and prostaglandin(s) in lipopolysaccharide-induced bone resorption in vivo. Infect Immun 70: 3915-3922.

16. Tanomaru J, Leonardo M, Filho MT, Filho IB, Silva L (2003) Effect of different irrigation solutions and calcium hydroxide on bacterial LPS. Int Endod J 36: 733-739.

17. Leonardo M, Salgado A, da Silva L, Filho MT (2003) Apical and periapical repair of dogs' teeth with periapical lesions after endodontic treatment with different root canal sealers. Pesqui Odontol Bras 17: 69-74.

18. Leonardo M, Hernandez M, Silva L, Tanomaru-Filho M (2006) Effect of a calcium hydroxide-based root canal dressing on periapical repair in dogs: a histological study. Oral Surg Oral Med Oral Pathol Oral Radiol Endod 102: 680-685.

19. Gottlow J, Nyman S, Karring T (1984) Healing following citric acid conditioning of roots implanted into bone and gingival connective tissue. J Periodontal Res 19: 214-220.

20. Karring T, Nyman S, Gottlow J, Laurell L (1993) Development of the biological concept of guided tissue regeneration--animal and human studies. Periodontol 2000 1: 26-35. 
Citation: Pereira YCL, Issa JPM, Watanabe E, Nascimento GC, lyomasa MM, et al. (2018) The Therapeutic Use of Propolis Extract in Alveolar Bone Contaminated with Bacterial Endotoxin. Dentistry 8: 473. doi:10.4172/2161-1122.1000473

Page 9 of 9

21. Passos G, Fernandes E, Campos M, Araújo J, Pesquero J, et al. (2004) Kinin B1 receptor up-regulation after lipopolysaccharide administration: role of proinflammatory cytokines and neutrophil influx. J Immunol 172: 1839-1847.

22. De Sousa J, Bueno P, Gregório L, Da Silva Filho A, Furtado N, et al. (2007) A reliable quantitative method for the analysis of phenolic compounds in Brazilian propolis by reverse phase high performance liquid chromatography. J Sep Sci 30: 2656-2665.

23. Weibel ER, Kistler GS, Scherle WF (1966) Practical stereological methods for morphometric cytology. J Cell Biol 30: 23-38.

24. Hayman AR (2008) Tartrate-resistant acid phosphatase (TRAP) and the osteoclast/immune cell dichotomy. Autoimmunity 41: 218-223.

25. Pileggi R, Antony K, Johnson K, Zuo J, Shannon Holliday L (2009) Propolis inhibits osteoclast maturation. Dent Traumatol 25: 584-588.

26. Park Y, Koo M, Abreu J, Ikegaki M, Cury J, et al. (1998) Antimicrobial activity of propolis on oral microorganisms. Curr Microbiol 36: 24-28.

27. Sforcin J, Orsi R, Bankova V (2005) Effect of propolis, some isolated compounds and its source plant on antibody production. J Ethnopharmacol 98: 301-305.

28. Solomonow M (2009) Ligaments: a source of musculoskeletal disorders. J Bodyw Mov Ther 13: 136-154.

29. Mostrova I, Baikusheva V (1969) Personal experience with Propolis anesthesia in the treatment of eental caries. Nauchni Tr Nauchnoizsled Stomatol Inst 13: 47-51.

30. Duarte S, Rosalen PL, Hayacibara MF, Cury JA, Bowen WH, et al. (2006) The influence of a novel propolis on mutans streptococci biofilms and caries development in rats. Arch Oral Biol 51: 15-22.

31. Coutinho A (2012) Honeybee propolis extract in periodontal treatment: A clinical and microbiological study of propolis in periodontal treatment. Indian J Dent Res 23: 294

32. Mohan PU, Uloopi KS, Vinay C, Rao RC (2016) In vivo comparison of cavity disinfection efficacy with APF gel, propolis, diode laser, and $2 \%$ chlorhexidine in primary teeth. Contemp Clin Dent 7: 45-50.

33. Sabir A (2016) The healing actions of propolis on direct pulp capping treatment: A review. Journal of Dentomaxillofacial Science 1: 186.

34. Isla M, Nieva Moreno M, Sampietro A, Vattuone M (2001) Antioxidant activity of Argentine propolis extracts. J Ethnopharmacol 76: 165-170.
35. Tůmová L, Pasavová D (2000) Allergic contact dermatitis caused by propolis. Ceska Slov Farm 49: 285-287.

36. Wagh VD (2013) Propolis: a wonder bees product and its pharmacological potentials. Adv Pharmacol Sci 2013: 308249.

37. Dodwad V, Kukreja BJ (2011) Propolis mouthwash: A new beginning. J Indian Soc Periodontol 15: 121.

38. Gebara ECE, Lima LA, Mayer M (2002) Propolis antimicrobial activity against periodontopathic bacteria. Brazilian J Microbiol 33: 365-369.

39. Tomomatsu N, Aoki K, Alles N, Soysa N, Hussain A, et al. (2009) LPSinduced inhibition of osteogenesis is TNF-alpha dependent in a murine tooth extraction model. J Bone Miner Res 24: 1770-1781.

40. Watanabe K, Iizuka T, Adeleke A, Pham L, Shlimon A, et al. (2011) Involvement of toll-like receptor 4 in alveolar bone loss and glucose homeostasis in experimental periodontitis. J Periodontal Res 46: 21-30.

41. Ossola CA, Surkin PN, Pugnaloni A, Mohn CE, Elverdin JC, et al. (2012) Long-term treatment with methanandamide attenuates LPS-induced periodontitis in rats. Inflamm Res 61: 941-948.

42. Kaunitz JD, Yamaguchi DT (2008) TNAP, TrAP, ecto-purinergic signaling, and bone remodeling. J Cell Biochem 105: 655-662.

43. Blair HC, Zaidi M, Schlesinger PH (2002) Mechanisms balancing skeletal matrix synthesis and degradation. Biochem J 364: 329-341.

44. Teitelbaum SL, Ross FP (2003) Genetic regulation of osteoclast development and function. Nat Rev Genet 4: 638-649.

45. Teitelbaum SL (2006) Osteoclasts; culprits in inflammatory osteolysis. Arthritis Res Ther 8: 201

46. Pileggi R, Antony K, Johnson K, Zuo J, Holliday LS (2009) Propolis inhibits osteoclast maturation. Dent Traumatol 25: 584-588.

47. Toker H, Ozan F, Ozer H, Ozdemir H, Eren K, et al. (2008) A morphometric and histopathologic evaluation of the effects of propolis on alveolar bone loss in experimental periodon-titis in rats. J Periodontol 79: 1089-1094.

48. Levi B, James A, Nelson E, Li S, Peng M, et al. (2010) Human AdiposeDerived Stromal Cells Stimulate Autogenous Skeletal Repair via Paracrine Hedgehog Signaling with Calvarial Osteoblasts. Stem Cells Dev 20: 243-257. 